\title{
One-stage versus two-stage lymph node dissection after investigation of sentinel lymph node in cutaneous melanoma: a comparison of complications, costs, hospitalization times, and operation times
}

Received: 1 March 2004 / Accepted: 3 March 2004 / Published online: 23 December 2004

(C) Springer-Verlag 2004

\begin{abstract}
The aim of the study was to evaluate whether complication rate, costs, operation times, and hospitalization times differed in two different patient groups: in group 1, frozen section analysis of the sentinel lymph node and lymph node dissection were carried out in the same operation. In group 2, normal investigation of the sentinel lymph node and lymph node dissection were done in a second operation. One hundred thirty-five patients with cutaneous melanoma were included. Hospitalization times, costs, complication rates, and operation times of two-stage and one-stage lymph node dissection of the draining area after detection of metastases in the sentinel lymph node were retrospectively compared. Lymph node metastasis in the sentinel lymph node was found in 23 patients. In 11 patients, removal of the sentinel lymph node and dissection of the lymph node basin was performed in the same operation. In 12 patients, a two-stage procedure was the treatment of choice. Operation times were not different in the two groups $(p=0.87)$ while two-stage operation patients were hospitalized significantly longer $(14.2 \pm 9.7$ vs $23.9 \pm$ 24 days; $p=0.01)$ and costs were significantly higher $(7,836.90 \pm 2,397.95$ Swiss francs vs 5,279.40 \pm 1,994.90 Swiss francs). In addition, more complications were found in the two-stage group.
\end{abstract}

Keywords Cost $\cdot$ Frozen section - Malignant cutaneous melanoma $\cdot$ Sentinel lymph node

O. E. C. von Känel $(\bowtie) \cdot$ M. Haug · G. Pierer

Klinik für Wiederherstellungschirurgie,

Kantonsspital Basel, Bruderholzrain 28,

4059 Basel, Switzerland

E-mail: gokado@bluewin.ch

Tel.: + 41-61-3312244

\section{Introduction}

Sentinel lymph node (SLN) removal and investigation is a suitable method to detect nonclinically suspicious lymph node metastases in patients with cutaneous malignant melanoma [1, 2]. Frozen section analysis of the sentinel lymph node, combined with removing the sentinel lymph node and dissection of the lymph node basin in the same operation is not as yet an accepted option [3, 4].

Material loss and low sensitivity are arguments against frozen section analysis of the sentinel lymph node [5].

In this study we evaluated whether performing frozen section analysis and dissection of the lymph node in the same intervention is associated with a change in duration of hospitalization, costs, operation time, and incidence of complications compared with the normal management as a two-stage procedure.

\section{Patients and methods}

Between 1 June 1996 and 1 June 2001, 135 patients with clinically nonmetastasized cutaneous melanoma (AJCC stage I or II) underwent a sentinel node procedure. In 125 patients the sentinel lymph node was examined by frozen section. In addition a wide local excision $(2 \mathrm{~cm})$ of the primary tumor was performed.

Frozen section analysis of the SLN and dissection of the corresponding lymph node basin as a-one step procedure was carried out in 13 patients (group 1). In another 13 patients, dissection of the corresponding lymph node basin was done in a second operation (group 2).

All charts of these patients with metastatic involvement of the sentinel lymph node were retrospectively reviewed, and the hospitalization times, costs, operation times, and postoperative complications of a one-stage and two-stage lymph node dissection were compared. In the two-stage dissection, operation times of the first and second operation were added, and the waiting time for the frozen section result was subtracted. 
Definition of complications

Infection

Presentation of an erythema or purulent secretion requiring antibiotic or operative treatment.

\section{Seroma}

Seroma was present if aspiration or operative intervention was required or if removal of the intraoperatively inserted drain was delayed (more than 8 days after operation).

\section{Wound problems}

Wound problems included wound dehiscence or necrosis which had to be treated by bedside or operative debridement.

\section{Hemorrhage}

Hemorrhage was present if a subcutaneous accumulation of blood required operative intervention.

\section{Results}

Patient and tumor characteristics are shown in Table 1.

Metastatic involvement of the sentinel lymph node was discovered by frozen section analysis in 13 patients. In these patients, dissection of the corresponding lymph node basin was performed during the same intervention. In one patient, frozen section was positive, but the final analysis could not confirm the diagnosis.

Table 1 Patient and tumor characteristics

\begin{tabular}{ll}
\hline Characteristic & $\begin{array}{l}\text { Number of patients } \\
\text { (unless otherwise indicated) }\end{array}$ \\
\hline Age (median) & 54 years \\
Gender & \\
Male & 68 \\
Female & 67 \\
Breslow thickness & \\
Median & $1.81 \mathrm{~mm}$ \\
$<1.5 \mathrm{~mm}$ & 74 \\
$1.5-4 \mathrm{~mm}$ & 43 \\
$>4 \mathrm{~mm}$ & 10 \\
Clark level & 0 \\
I & 10 \\
II & 59 \\
III & 49 \\
IV & 4 \\
V & \\
Location primary tumor & 7 \\
Head-neck & 62 \\
Extremities & 66 \\
Trunk & \\
\hline
\end{tabular}

In another nine patients, frozen section was negative and metastases were found after immunohistological investigation. The sensitivity of frozen section investigation was thus $59 \%$, the specificity $99 \%$ (pos. pred. value: $92.8 \%$; neg. pred. value: $93.1 \%$ ).

Four of the ten patients in whom the sentinel lymph node was not analyzed by frozen section, showed metastatic involvement of the SLN, and a dissection of the lymph node basin was performed at a second intervention.

Group 1 (13 patients) was compared with the pathological investigation of the SLN and dissection of the corresponding lymph node basin in the same operation with group 2 (13 patients), where the operation was done as a two-stage procedure (nine frozen section false negative results and four primary planned two-stage operations). Hospitalization time of the group 1 was $23.9 \pm 24$ days versus $14.2 \pm 9.7$ days $(p=0.013)$ of group 2 (Tables 2 and 3 ).

In group 2 the complications occurred more frequently than in group 1 (one-stage operation). In group 1 , there were two wound complications (two hematomas) while in the second group five complications had to be treated. Nevertheless, the difference between the groups was not significant $(p=0.14)$ (Table 4$)$.

Comparing the groups with and without complications, no significant difference could be found due to gender, age, and operation duration of the patients.

Table 2 Comparison of duration of hospitalization: one-stage versus two-stage operation

\begin{tabular}{lllll}
\hline $\begin{array}{l}\text { Duration of } \\
\text { hospitalization }\end{array}$ & Number & $\begin{array}{l}\text { Mean } \\
\text { (days) }\end{array}$ & $\begin{array}{l}\text { Standard } \\
\text { deviation }\end{array}$ & $p$ Value \\
\hline $\begin{array}{l}\text { One-stage operation } \\
\text { Two-stage operation }\end{array}$ & 11 & $\begin{array}{l}14.25 \\
23.9\end{array}$ & $\begin{array}{l} \pm 9.7 \\
\pm 23.9\end{array}$ & 0.013 \\
\hline
\end{tabular}

Table 3 Comparison of complications: one-stage versus two-stage operation

\begin{tabular}{llll}
\hline Local complications & Total & $\begin{array}{l}\text { All in one } \\
\text { operation }\end{array}$ & $\begin{array}{l}\text { Twice } \\
\text { operated }\end{array}$ \\
\hline Number & 26 & 13 & 13 \\
Seroma & 2 & 0 & 2 \\
Necrosis of wound edge & 1 & 0 & 1 \\
Infection & 2 & 0 & 2 \\
Hematoma & 2 & 2 & 0 \\
No complications & 21 & 11 & 8 \\
\hline
\end{tabular}

Table 4 Comparison of local complications: one-stage versus twostage operation

\begin{tabular}{llll}
\hline Local complications & $\begin{array}{l}\text { Number } \\
\text { (with/without) }\end{array}$ & Percentage & $p$ Value \\
\hline One-stage operation & $2 / 13$ & 15 & \\
Two-stage operation & $5 / 13$ & 38 & 0.14 \\
\hline
\end{tabular}


Table 5 Comparison of duration of operation: one-stage versus two-stage operation. SLN Sentinel lymph node

\begin{tabular}{lllll}
\hline Duration of operation & Number & $\begin{array}{l}\text { Mean } \\
\text { (minutes) }\end{array}$ & $\begin{array}{l}\text { Standard } \\
\text { deviation }\end{array}$ & $p$ Value \\
\hline SLN total & 11 & 172.7 & 99 & \\
SLN blue stained & 11 & 166.4 & 82 & 0.87 \\
\hline
\end{tabular}

Table 6 Comparison of costs: one-stage versus two-stage operation

\begin{tabular}{lllll}
\hline Costs & Number & $\begin{array}{l}\text { Mean } \\
\text { (Swiss francs) }\end{array}$ & $\begin{array}{l}\text { Standard } \\
\text { deviation }\end{array}$ & $p$ Value \\
\hline One-stage operation & 11 & $5,279.40$ & $1,994.90$ & \\
Two-stage operation & 11 & $7,836.90$ & $2,397.95$ & 0.0132 \\
\hline
\end{tabular}

The operation duration of the two-stage group 2 was $166.4 \pm 82 \mathrm{~min}$ compared with $172.7 \pm 99 \mathrm{~min}$ $(p=0.87)$ for the first group (Table 5).

The mean time of frozen section analysis was $25 \mathrm{~min}$ (range, $10-60 \mathrm{~min}$ ).

The cost per patient in group 1 was $7,836.90 \pm 2,397.95$ Swiss francs versus 5,279.40 \pm $1,994.90$ Swiss francs $(p=0.0132)$ in group 2 (Table 6).

\section{Discussion}

Frozen section analysis necessitates dissection of the sentinel lymph node and removal of the lymph node basin during the same intervention. Besides the sensitivity and specificity, the duration of operation, costs, duration of hospitalization, and incidence of complications are important factors in evaluating the advantages of this procedure.

Systemic complications were rare in both groups and mainly due to a perioperative gastritis and a suspected cardiac event. However, the incidence of minor complications was different in the two groups. While $15 \%$ $(2 / 13)$ of the patients in group 1 suffered from wound complications, $38 \%(5 / 15)$ of the patients in group 2 showed local complications. In group 1, two hematomas needed an operative evacuation. Wound infections did not occur in this group.

In group 2, wound infections occurred in two cases. In addition we had two seromas and one skin necrosis.

Reviewing the literature, we find that a wide variation of complication rates are described. Our overall local complication rate was $25 \%$. The rate of wound infection, hemorrhage, and seroma was $7 \%$ in each; the rate of wound dehiscence/necrosis was $4 \%$. While in the literature the rate of wound dehiscence/necrosis $(3-26 \%)$, wound infection (9-29\%), and hemorrhage (0-8\%) do not differ significantly from our rates, seromas occurred much less frequently in our series. This might be due to the different use of the definition of "local complication." In our series of a few patients the drain was not removed before day 8 and as our definition of seroma was if removal of the drain was after this period these patients were considered to be free of complications. On the other hand our number of patients was lower compared with other studies [6-10].

In our study, hospitalization time of the group 1 (one-stage operation patients) was significantly shorter $(p=0.013)$ than in group $2 \quad(14.2 \pm 9.7$ days vs $23.9 \pm 24$ days). An explanation therefore could be found in the higher incidence of local complications in patients of group 2. One patient with a fistula stayed in the hospital 44 days; another patient who presented with necrosis of the wound edges stayed in for 35 days.

We found no significant difference in operation time between the one-stage operation group 1 and the twostage operation group $2(p=0.87)$. Operation time of the first group was $172.7 \pm 99 \mathrm{~min}$ on average, compared to $166.4 \pm 82 \mathrm{~min}$ in the second group. The time of waiting for the result of frozen section analysis could be used to perform the excision of the biopsied primary tumor or the excision of a second sentinel lymph node if lymphoscintigraphy showed a second corresponding lymph basin. This is one reason that, even when performing a frozen section analysis of the sentinel lymph node, the operation time was not significantly longer in the one-stage operation group.

Costs per patient were significantly lower in the group 1 (one-stage operation patients) than in the group $2 \quad(5,279.40 \pm 1,994.90 \quad$ Swiss francs vs $7,836.90 \pm 2,397.95$ Swiss francs; $p=0.0132)$. The additional costs $(2,557.50$ Swiss francs per patient) resulted from the additional histological analysis (frozen section) and longer hospitalization time. Further, the fact that the first few days of hospitalization and the first few minutes of an operation are the most expensive at our hospital contributed to other minor expenses in the two-stage operation patients.

\section{Conclusion}

The sensitivity of frozen section investigation was 59\% in our study. Nevertheless, we suggest that frozen section analysis of the sentinel lymph node is performed, because when performed with dissection of the lymph node basin in the same intervention it lowers the costs and complication rate, and leads to a significantly shorter hospitalization time. On the other hand, the operation time was not significantly different between the two groups.

\section{References}

1. Morton DL, Wen DR, Wong JH, Economou JS, Cagle LA, Storm FK, Foshag LJ, Cochran AJ (1992) Technical details of intraoperative lymphatic mapping for early stage melanoma. Arch Surg 127(4):392-399

2. Stanley P (2000) The role of sentinel lymph nodes in malignant melanoma. Surg Clin North Am 80(6):1741-1757 
3. Koopal SA, Tiebosch AT, Albertus Piers D, Plukker JT, Schraffordt Koops H, Hoekstra HJ (2000) Frozen section analysis of sentinel lymph nodes in melanoma patients. Cancer 89(8): 1720-1725

4. Viale G, Bosari S, Mazzarol G, Galimberti V, Luini A, Veronesi P, Paganelli G, Bedoni M, Orvieto E (1999) Intraoperative examination of axillary sentinel lymph nodes in breast carcinoma patients. Cancer 85(11):2433-2438

5. van Diest PJ, Peterse HL, Borgstein PJ, Hoekstra O, Meijer CJ (1999) Pathological investigation of sentinel lymph nodes. Eur J Nucl Med 26[Suppl 4]:S43-S49

6. Bland KI, Klamer TW, Polk HC Jr, Knutson CO (1981) Isolated regional lymph node dissection: morbidity, mortality and economic considerations. Ann Surg 193(3):372-376
7. Urist MM, Maddox WA, Kennedy JE, Balch CM (1983) Patient risk factors and surgical morbidity after regional lymphadenectomy in 204 melanoma patients. Cancer 51(11):21522156

8. Karakousis CP, Heiser MA, Moore RH (1983) Lymphedema after groin dissection. Am J Surg 145(2):205-208

9. Karakousis CP, Emrich LJ, Rao U (1986) Groin dissection in malignant melanoma. Am J Surg 152(5):491-495

10. Baas PC, Schraffordt Koops H, Hoekstra HJ, van Bruggen JJ, van der Weele LT, Oldhoff J (1992) Groin dissection in the treatment of lower-extremity melanoma: short-term and longterm morbidity. Arch Surg 127(3):281-286 